\title{
The histology and cytology of changes in the epithelium of the cervix uteri ${ }^{1}$
}

\author{
A. D. T. GOVAN, R. M. HAines, F. A. LANGLEY, C. W. TAYLOR, \\ AND A. S. WOODCOCK ${ }^{2}$
}

From the Royal College of Obstetricians and Gynaecologists, London

SYNOPSIS Abnormalities of the cervical epithelium are set out in two main groups: bland lesions which are regarded as unrelated to malignancy, and malign lesions which are considered as potential precursors of invasive carcinoma. The histological features of each condition and the cytological pattern of the corresponding cervical smear are described and correlated.

Cone biopsy is advocated as the only satisfactory form of cervical biopsy for both the diagnosis and evaluation of lesions such as dysplasia and carcinoma in situ. It is emphasized that further study is necessary to determine their natural history and prognosis in relation to invasive carcinoma.

It is now widely accepted that certain abnormalities of structure and arrangement in the cells of cervical squamous epithelium may be the precursor of invasive carcinoma. These changes within the epithelium are termed mild or severe dysplasia according to their severity, and in their extreme form are described as carcinoma in situ.

Usually these abnormalities produce no signs or symptoms, and are not detectable at ordinary clinical examination. Cytology, however, by the study of cells scraped or exfoliated from the cervix, provides a routine screening method. The discovery of cells in the cytological smear suggestive of severe dysplasia or carcinoma in situ is an indication for cervical cone biopsy. It is not only in the interests of the patient that these lesions should be detected in this way, but it also provides material for further study of their relationship to invasive carcinoma, a subject on which there is as yet little precise information. If such a study is to be valid, then there must be uniformity in the terminology and histological criteria used in assessing the lesions. This paper attempts to describe and classify abnormalities of the cervical epithelium in a manner suited to this purpose. Many of the views expressed have crystallized from the study the authors were asked to make of histological material in the survey of carcinoma in situ being carried out by the Royal College of Obstetricians and Gynaecologists (Govan, Haines, Langley, Taylor, and Woodcock, 1966).

${ }^{1}$ Copies of this paper may be obtained from the Publishing Manager, B.M.A. House, Tavistock Square, London, price 5 s each, the envelope marked, Journal of Clinical Pathology, BROADSHEE IS.

${ }^{2}$ The authors of this report are the members of a panel appointed by the Royal College of Obstetricians and Gynaecologists.
The paper deals particularly with dysplasia and carcinoma in situ, but includes other changes which, although unrelated in their natural history, have histological patterns sometimes confused with these conditions. Clinically invasive carcinoma is not discussed. The detection of abnormalities in the cervical smear is often the first step in the diagnostic sequence of the more serious lesions; for this reason an attempt is also made at a broad correlation between the histological appearances in the biopsy specimen and the cytological pattern of the corresponding smear. It is of great practical importance in discussing any abnormality of the cervical epithelium to decide whether or not it is related to carcinoma. The changes are therefore described in two main groups: first, bland lesions which are regarded as having no proclivities for malignant change, and secondly malign lesions which are considered to be potential, though not invariable, precursors of invasive carcinoma.

\section{CHANGES IN CERVICAL EPITHELIUM}

BLAND LESIONS These are subdivided into squamous hyperplasia (reactive hyperplasia and basal cell hyperactivity), reserve cell proliferation, and metaplasia incomplete and complete.

MALIGN LESIONS The categories for malign lesions are dysplasia (mild and severe), carcinoma in situ, and microcarcinoma.

\section{BLAND LESIONS}

SQUAMOUS HYPERPLASIA Squamous hyperplasia, an 
orderly thickening of the squamous epithelium of the cervix, occurs in two main forms.

Reactive hyperplasia This form consists in a thickening of the whole epithelium. It is seen in some chronic irritative conditions and particularly as a result of prolapse. The surface usually shows hyperkeratosis with parakeratosis of varying degree; the basal layers may be fragmented and the rete pegs are often lengthened and broadened. There is no cellular atypism and maturation is normal.

Basal cell hyperactivity This form is of unknown aetiology. The basal layers of the epithelium proliferate to form several instead of the usual one or two layers. There are only very few mitoses, but the component cells have rather large nuclei and basophilic cytoplasm suggesting increased activity. The upper layers of the epithelium are mature and normally stratified.

A regenerating epithelium also may show activity of its cells. These may be slightly irregular in arrangement and may make up the whole thickness of the thin re-forming epithelium. There are, however, attempts at maturation, especially towards the edges where the new epithelium merges with the normal.

No disturbing cytological changes occur in the smear from either form of squamous hyperplasia, for there is no cellular atypism in these variants. In reactive hyperplasia with hyperkeratosis this will be reflected in the smear by a preponderance of superficial squames, some of them anuclear. This pattern will be particularly noticeable when it occurs in the

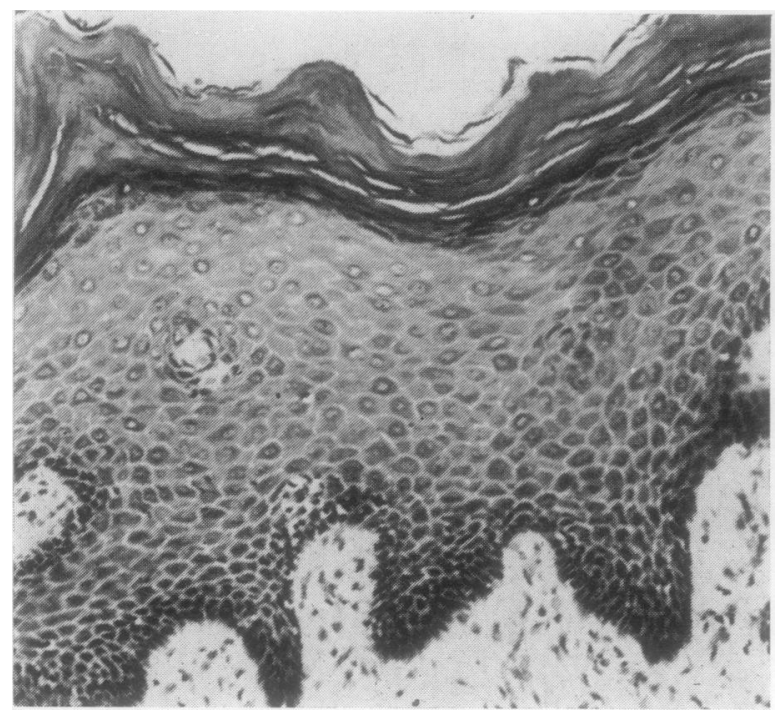

FIG. 1. Reactive squamous hyperplasia: an orderly thickening of the stratified epithelium with keratinization.

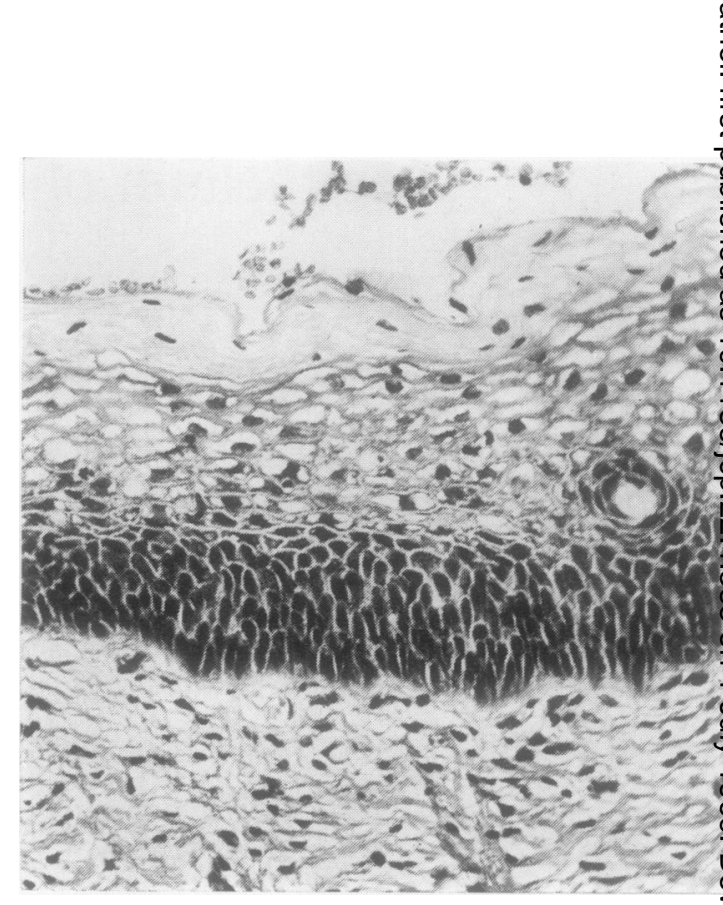

FIG. 2. Basal cell hyperactivity: several layers of active basal cells are covered by squames.

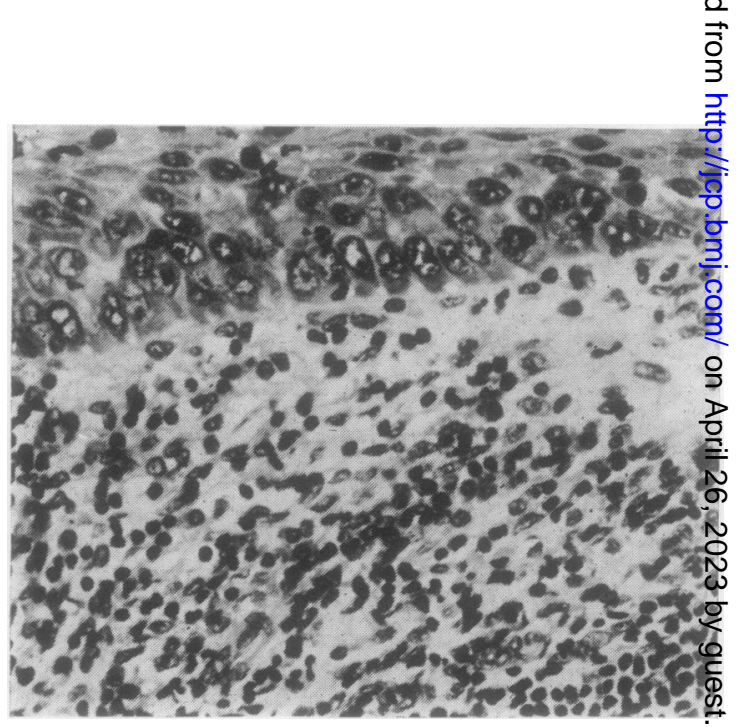

FIG. 3. Regenerating epithelium: immature but not undul active cells make up most of the epithelium. More matur cells at the right merge into normal epithelium. 


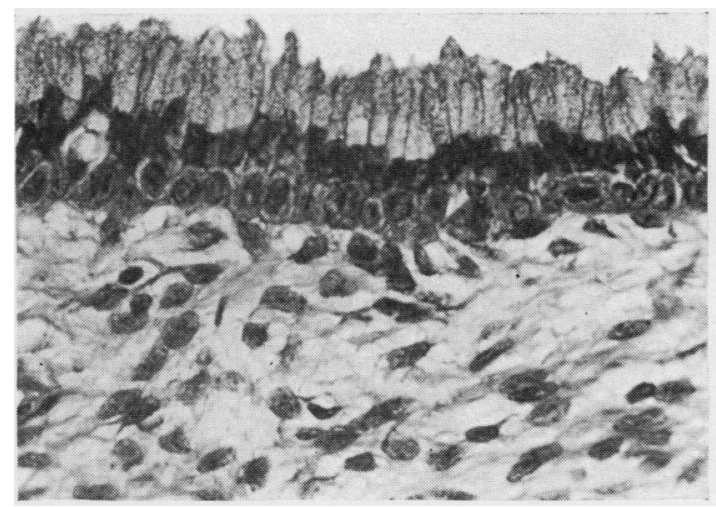

FIG. 4.

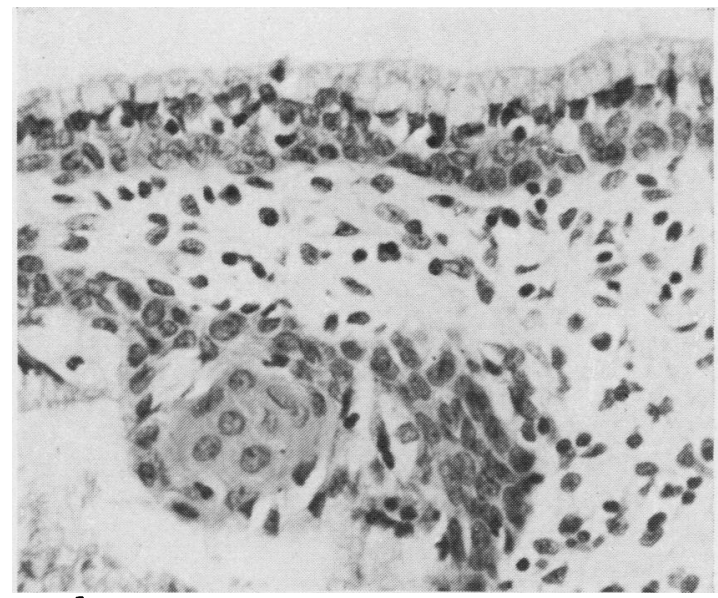

elderly, postmenopausal patient, whose smear would normally lack this cell type, but who has in this instance severe uterine prolapse. In basal cell hyperactivity the smear will as a rule be uninformative, for the Ayre's spatula used to obtain the sample of cells will not reach the deeper layers. Occasionally a few basal cells may be present and these will have slightly larger nuclei than is normal. In the smear from a regenerating squamous epithelium similar rounded cells with slightly enlarged, bloated nuclei may be found. These cells are sometimes numerous, and if areas of ulceration remain on the cervix there may also be a considerable number of inflammatory cells including histiocytes. The cytological abnormalities, however, are slight and should not produce diagnostic difficulties.

RESERVE CELL PROLIFERATION A layer of small cells, patchy in distribution and inconspicuous, is often present immediately beneath the columnar epithelium of the cervix. In some conditions, such as erosion or polyp, these cells proliferate to form several layers but remain orderly. The clusters of cells form not only beneath the surface epithelium but also around the gland crypt.

The degree of proliferation of these so-called reserve cells varies, and when marked may merit the term 'reserve cell hyperplasia'. At scanning magnifications the intricate multilayering may be confused with the appearances of carcinoma in situ, especially when the process involves gland crypts, but on detailed examination it is distinguished by the orderly and uniform structure of the component cells.

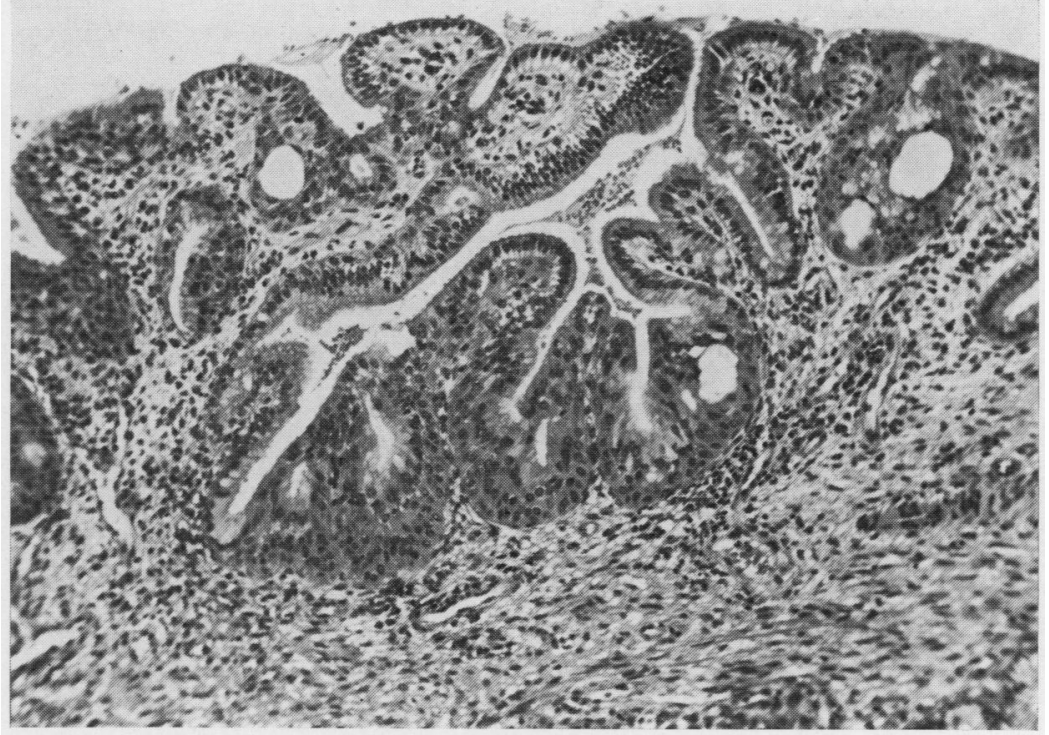

FIG. 4. Reserve cell

proliferation: a single layer of orderly reserve cells lies

beneath the columnar

epithelium of the endocervix.

FIG. 5. Reserve cell

proliferation: reserve cells have proliferated beneath the columnar epithelium of gland crypts.

FIG. 6. Reserve cell proliferation: reserve cells form a layer beneath the surface columnar epithelium and have proliferated around a gland crypt.

FIG. 6 . 
Reserve cell proliferation produces no characteristic changes in the cervical smear.

METAPLASIA Metaplasia is a change from a columnar to a squamous type of epithelium. It usually stems from a proliferation of the reserve cells and a variety of appearances results according to the stage and extent of the transformation. The process can be conveniently considered under two headings, incomplete metaplasia and complete metaplasia.

Incomplete metaplasia is a stage at which remnants of the columnar epithelium are still recognizable as the replacement by squamous epithelium continues. Early in the process layers of proliferating reserve cells form a sheet of squamoid epithelium with a ribbon of columnar cells on its surface. These cells may be of typical, well formed endocervical pattern, but more often they are degenerate, or may be stunted and peg-shaped without obvious mucous secretion. As metaplasia proceeds the pattern becomes more confusing. The columnar cells are engulfed by the proliferating reserve cells and a haphazard mixture of mucus-secreting and squamoid cells results. The mucous cells degenerate, becoming bloated and distorted; they may burst, leaving only tiny lacunae, some containing mucus, some polymorphs, in the depths of the new epithelium. The bizarre appearances which result can cause difficulties in interpretation and may be mistaken for carcinoma in situ. Careful examination, however, will show that the proliferating reserve cells are orderly as regards the size, shape, and chromatin distribution of their nuclei. The irregularities are due to degenerative changes in the scattered mucous cells and these may be demonstrated more clearly by the use of stains such as mucicarmine or alcian blue.

Complete metaplasia, sometimes termed epidermidization, is the state when the columnar cells are replaced entirely by irregular plaques of new epithelium which is squamous in type, but incompletely stratified. The change is usually patchy in distribution but can be extensive. It is not limited to surface epithelium but may involve gland crypts, and is then particularly liable to be mistaken for carcinoma. However, the epithelium, although incompletely stratified, is composed of mature cells without mitoses or nuclear atypism. In contrast to the irregular pattern of invasive carcinoma, the metaplastic epithelium maintains the contours of the surface mucosa and the smooth outlines of gland crypts.

In the smear, swollen, distorted endocervical cells may be seen in incomplete metaplasia but similar cells occur in other conditions such as erosion, which may indeed coexist. Sometimes a cluster of these endocervical cells gives difficulty in interpretation, but as a rule there are occasional cells at the

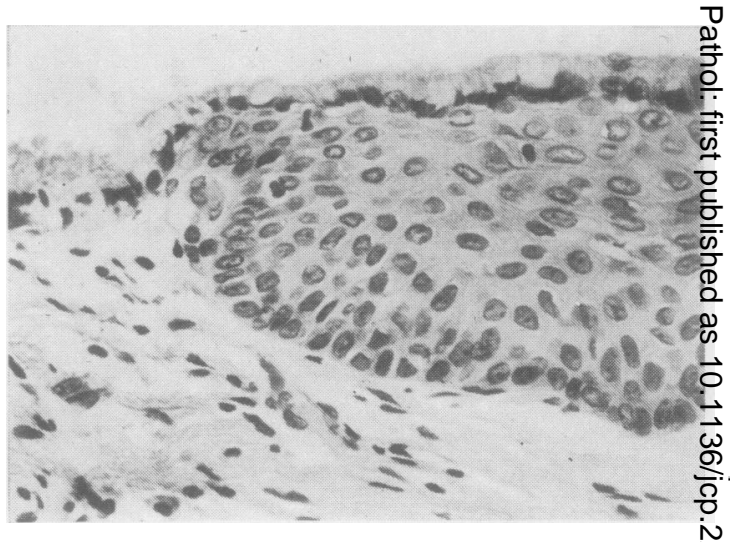

FIG. 7. Metaplasia: a sheet of squamoid epithelium, the result of reserve cell proliferation, lies under an intakt columnar epithelium.

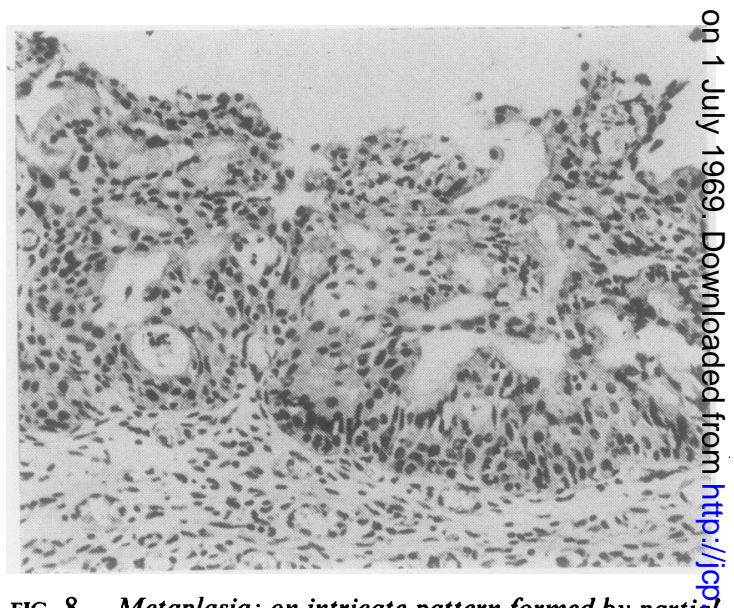

FIG. 8. Metaplasia: an intricate pattern formed by partiog replacement of the columnar by squamoid epithelium.

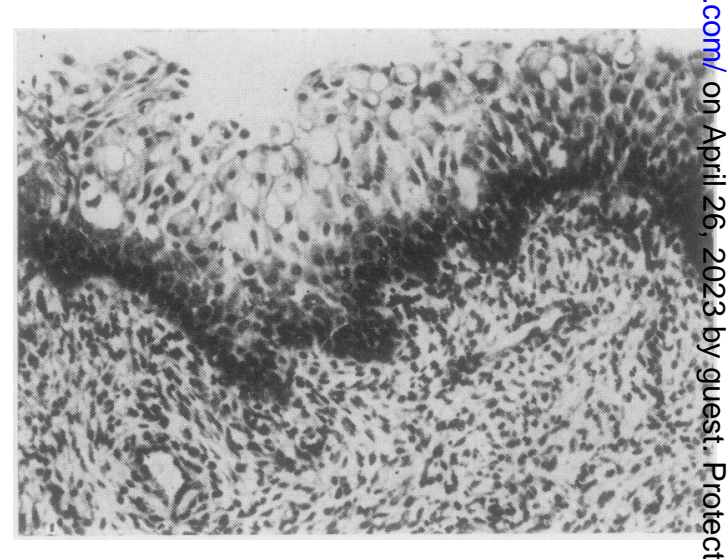

FIG. 9. Metaplasia: on the left, bloated mucous celis intermingle with squamous cells and distort the patter of the epithelium. 


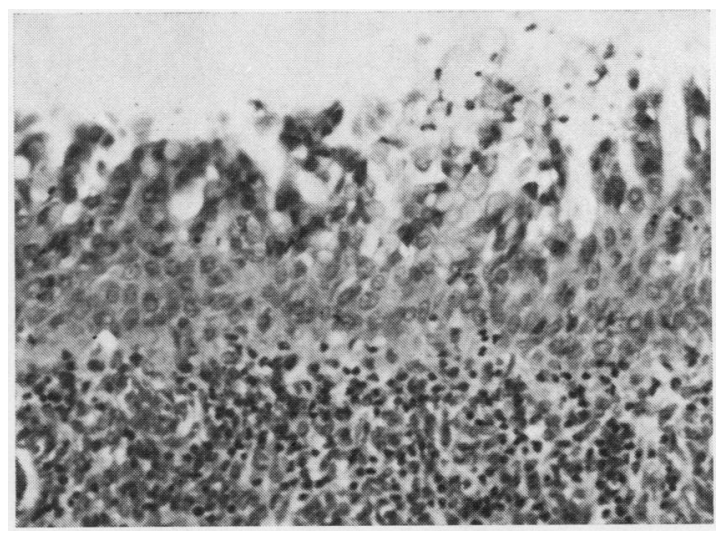

FIG. 10. Metaplasia: squamous cells occupy the basal portion of the epithelium. The fragmented upper layers contain mucous cells which could be identified more clearly by special stains.

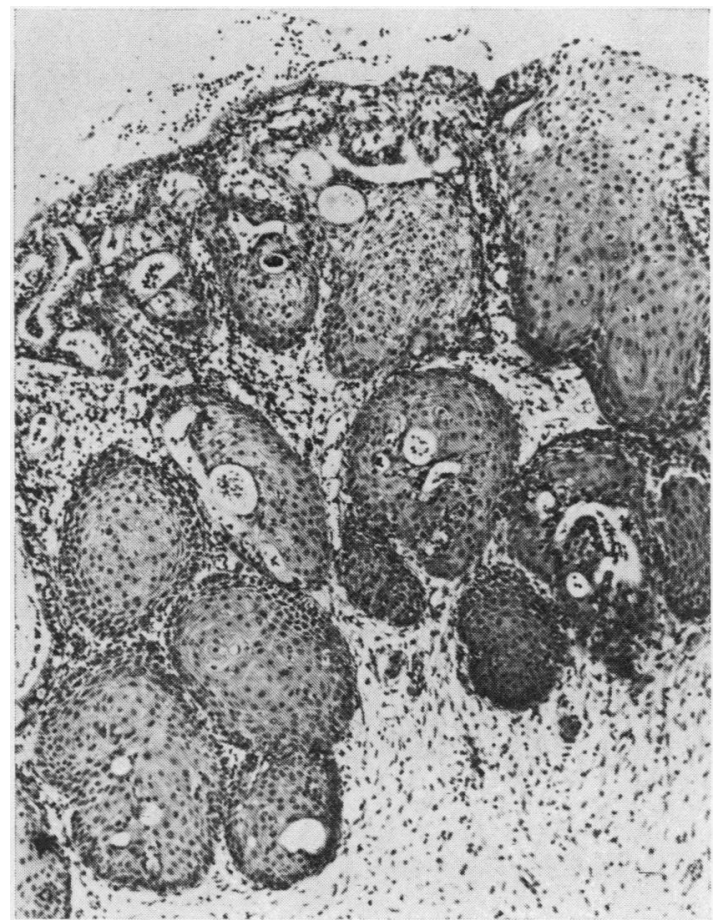

FIG. 11. Metaplasia: mature squamoid epithelium completely replaces the columnar epithelium but the outline of the crypts remains. periphery of the cluster which maintain sufficient of the characteristic columnar outline for identification of cell type. Most of the nuclei are of typical, orderly, vesicular pattern with prominent nucleoli. A few nuclei may be irregular, but the abnormalities are degenerative, consisting mainly of swelling and blurring due to karyolysis. There are no specific changes in the smear in complete metaplasia.

\section{MALIGN LESIONS}

The changes in the epithelium so far described, although occasionally misinterpreted as malignant, have in fact no known relationship to carcinoma. In contrast, the lesions now to be discussed are termed malign because all show in some measure abnormalities of cell structure and arrangement which relate them to malignancy. Nevertheless, mild dysplasia differs considerably in clinical significance from severe dysplasia and carcinoma in situ, for not infrequently it results from an inflammatory cause such as infection with trichomonas and is then usually reversible.

Severe dysplasia and carcinoma in situ, on the other hand, carry a far more serious risk of eventual progression to invasive cancer.

DYSPLASIA The two grades of dysplasia are distinguished histologically by the degree of cellular irregularity.

Mild dysplasia The cells do not lose polarity and stratification is maintained. Maturation and differentiation are perverted, however, so that the dysplastic epithelium becomes a caricature of the normal. The predominant feature of the cells is that nucleus and cytoplasm are out of step. The cytoplasm differentiates relatively normally, although sometimes individual cells at various levels in the epithelium show premature cornification. In contrast, the nucleus tends to be large, slightly irregular in outline and may be hyperchromatic. The changes are most evident in the upper layers of the epithelium where many of the cells have a normal cytoplasmic content, but enlarged, misshapen nuclei. Superimposed degenerative changes, such as karyorrhexis and the formation of halo-like clear zones round the nuclei, are a usual feature of dysplasia and accentuate the abnormalities. Often pallor and shrinkage of cytoplasm make intercellular bridges conspicuous.

The smear from mild dysplasia mirrors these epithelial changes. The individual cells are clearly recognizable as of superficial, intermediate or basal layer origin, but have the characteristic feature of an irregular nucleus which is immature in relation to the cytoplasmic content of the cell. Invariably 


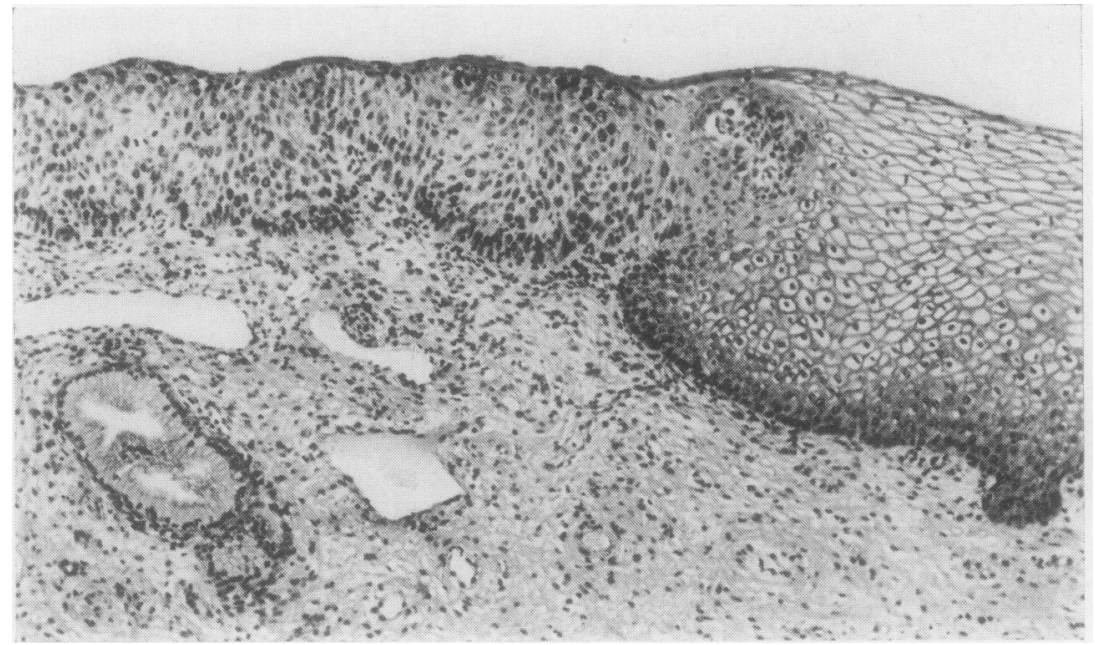

FIG. 12.

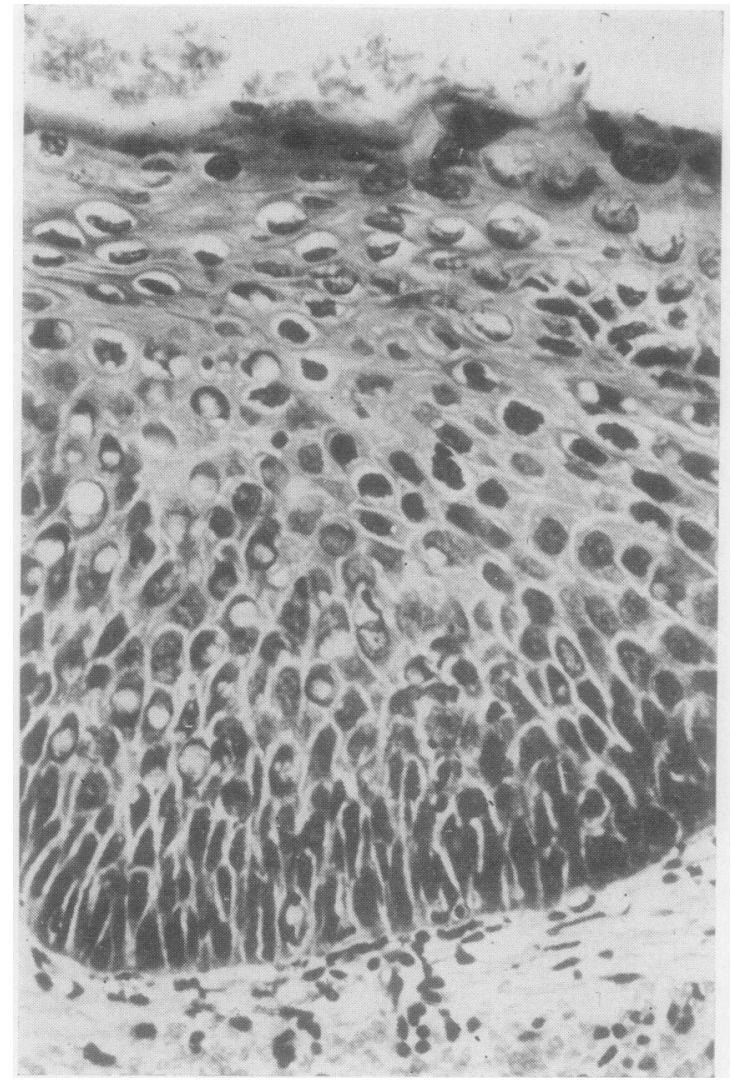

FIG. 14.

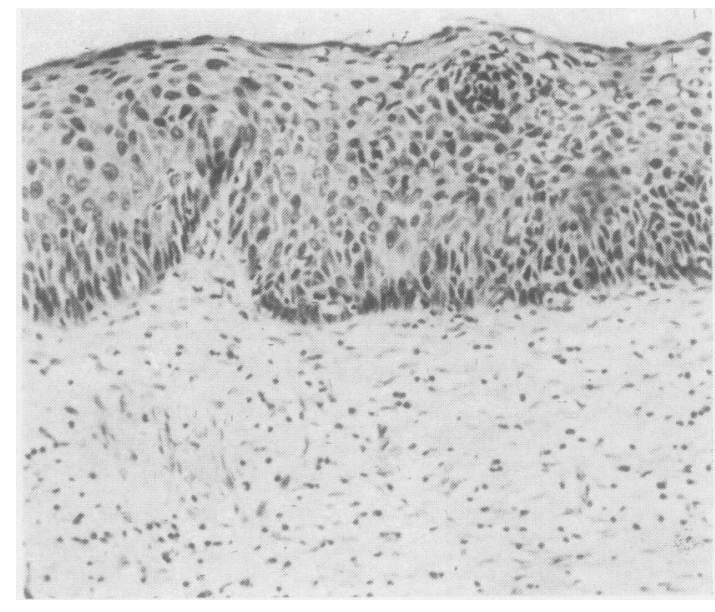

FIG. 13.

FIG. 12. Dysplasia: there is a contrast between normal 음 and dysplastic epithelium.

FIG. 13. Mild dysplasia: immature cells with large hyperchromatic nuclei are scattered through the epithelium but $\sigma$ there is stratification and cells in the upper layers show $\mathrm{N}$ maturation.

స్ట

FIG. 14. Mild dysplasia: pyknosis, karyorrhexis, and perinuclear haloes in the abnormal cells, at higher magni-fication.

FIG. 15: Mild dysplasia: some of the abnormal cells show $\stackrel{\text { क्ष }}{+}$ severe degenerative changes.

FIG. 16. Severe dysplasia: the epithelium is composed of $\overline{\mathrm{D}}$ pleomorphic cells. Stratification is just discernible in the $\frac{O}{\mathbb{D}}$ thin upper layers.

FIG. 17. Severe dysplasia: pleomorphism at higher magnification, with both proliferation and degeneration of cells. O 


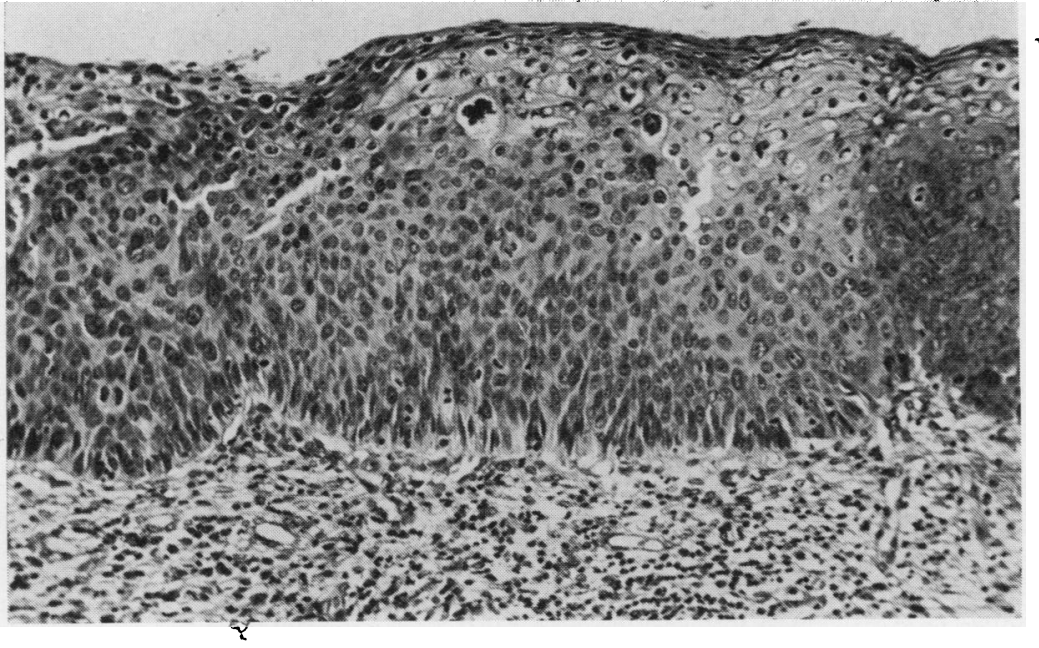

FIG. 15 .

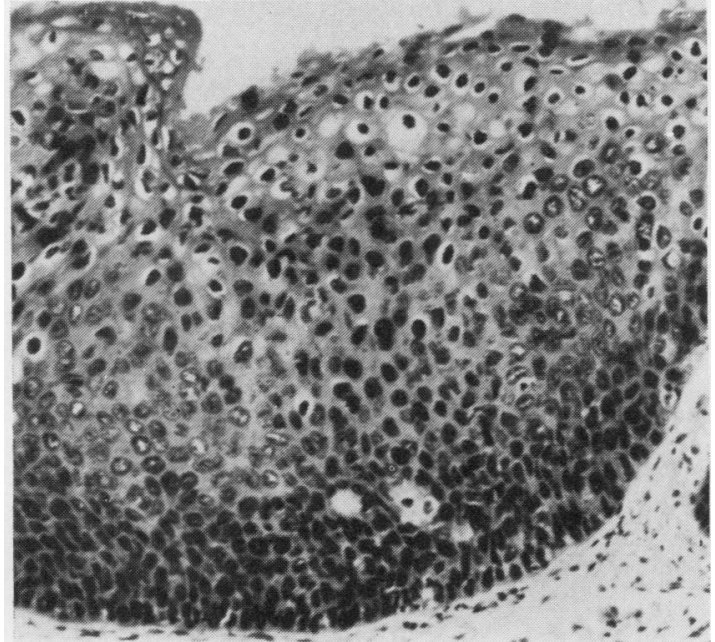

FIG. 16 .

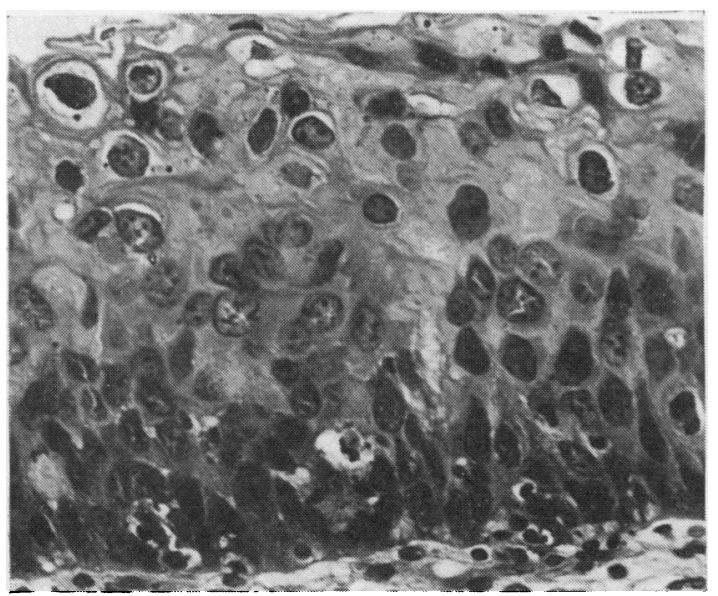

FIG. 17. superficial and intermediate squames predominate. The superficial squames have pyknotic nuclei which are larger than normal and often slightly misshapen. The nuclei of the intermediate squames are enlarged and mildly irregular, but there is little clumping of chromatin and the upset in nucleo-cytoplasmic ratio produced by the nuclear enlargement is only slight. Degenerative changes are conspicuous and there may be perinuclear halos in both superficial and intermediate squames, particularly when the dysplasia is associated with trichomonas infection. The term dyskaryotic has become established to describe cells of the above pattern, perhaps to emphasize that nuclear and not cytoplasmic abnormalities are their characteristic. Thus the report of dyskaryotic cells in a smear implies that they arise from an epithelium which is itself dysplastic.

Severe dysplasia The cells are much more irregular than in mild dysplasia, both in morphology and arrangement. There is only a poor attempt at maturation and stratification of the epithelium is barely discernible. The nuclei are greatly misshapen, usually hyperchromatic and their chromatin is coarsely clumped. There may be bizarre mitoses at varying levels in the epithelium. A distinction between severe dysplasia and carcinoma in situ is sometimes extremely difficult. A diagnosis of dysplasia can be made firmly if there is evidence of true stratification, but stratication must not be confused with the layer of flattened cells not infrequently seen on the surface of carcinoma in situ. Often the opinion can only be based somewhat arbitrarily on the impression that there is less crowding of nuclei in the upper than the lower layers. The abnormal epithelium is easily dislodged. If the surface layers 


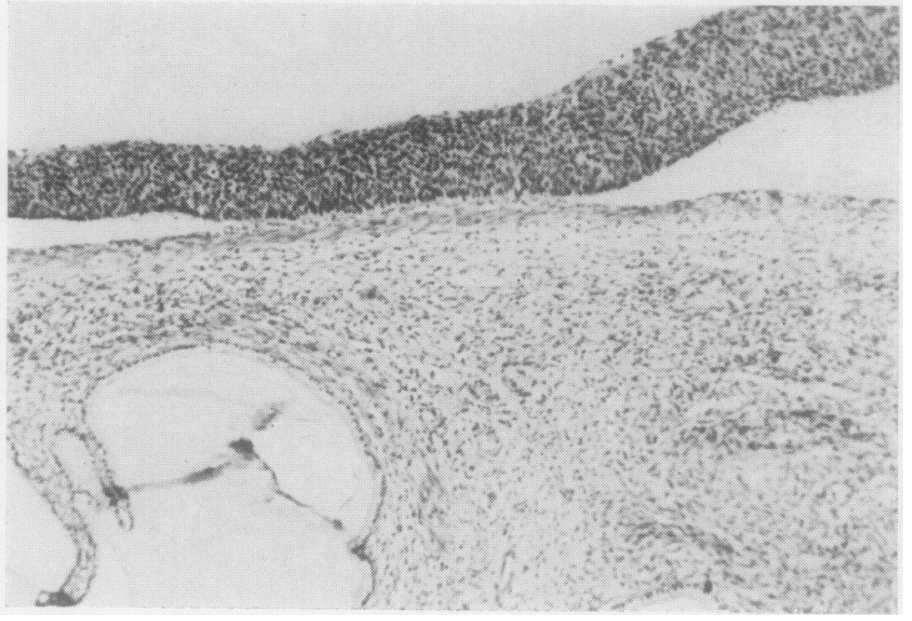

FIG. 18.

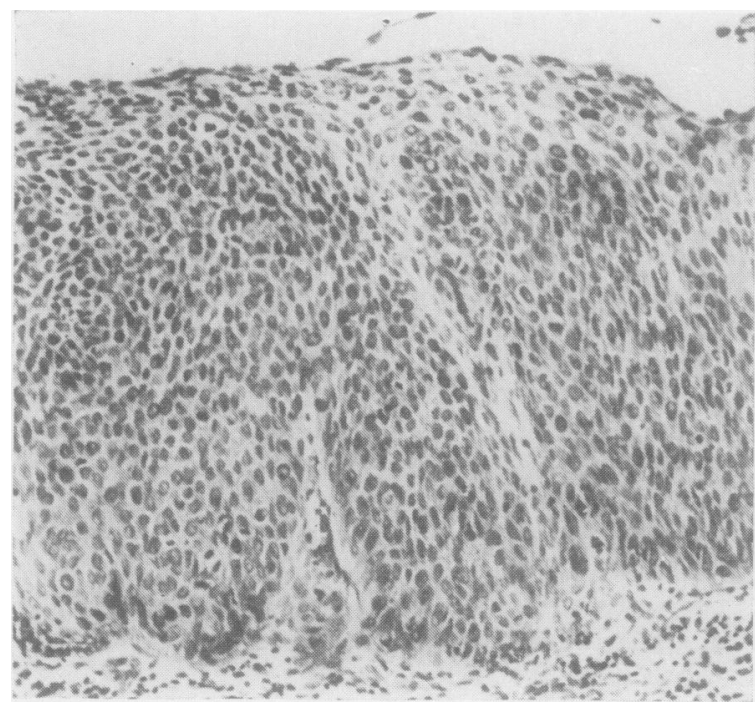

FIG. 19.

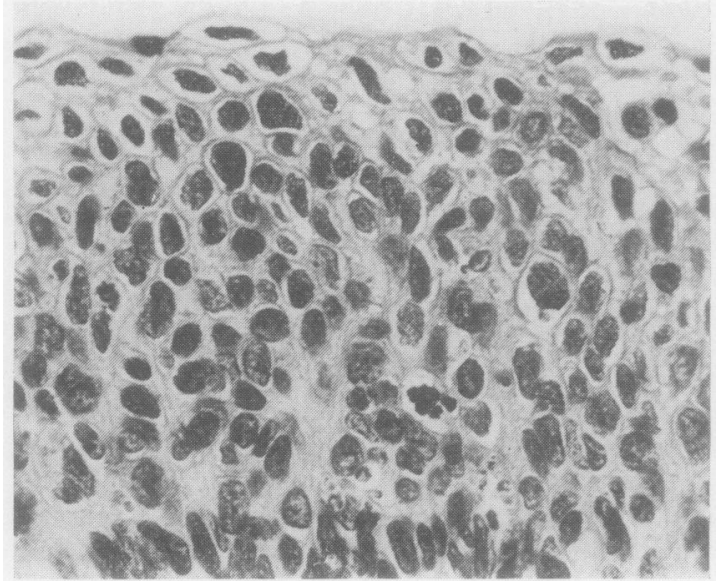

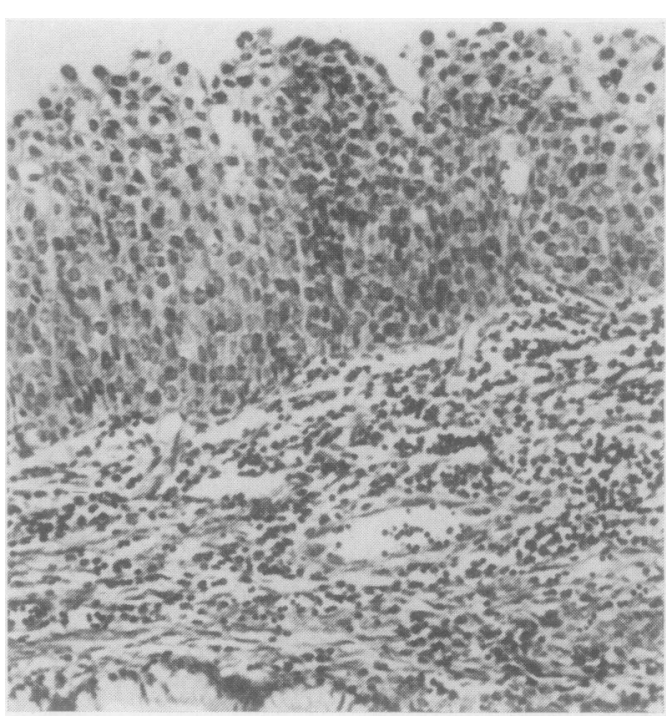

FIG. 21.

FIG. 18. Malign epithelium: the epithelium in dysplasia oิ and in carcinoma in situ is fragile and is easily displaced. N

FIG. 19. Carcinoma in situ: undifferentiated cells crowd $\mathrm{\omega}$ the whole thickness of the epithelium and stratification is lacking.

FIG. 20. Carcinoma in situ: pleomorphic cells with large hyperchromatic nuclei showing an increased nucleocytoplasmic ratio.

FIG. 21. Carcinoma in situ: abnormal cells escape from the fragmenting epithelium.

FIG. 20. 
of cells have been lost due to such cause as the recent taking of smears or swabbing before the biopsy, then the distinction from carcinoma in situ may be impossible.

The smear in severe dysplasia contains cells in which nuclear abnormalities are conspicuous. The chromatin is clumped and usually hyperchromatic; the nuclear membrane is often irregular and wrinkled. These appearances in the nucleus resemble those of malignant cells, but, despite their enlarged misshapen nuclei, the majority of cells maintain an essentially normal outline and cytoplasmic content so that they can be recognized as dyskaryotic rather than malignant. Sometimes, however, when the smear is from a severe dysplasia barely distinguishable histologically from carcinoma in situ there may be a quite considerable upset in nucleocytoplasmic ratio. It may then be difficult or impossible to decide whether the cells are dyskaryotic or malignant. Occasionally a similar difficulty arises when a smear contains cells from the surface layers of a fairly well differentiated invasive carcinoma. These cells may appear dyskaryotic. In both instances the problem is academic, for such severe abnormalities in a smear, regardless of their precise interpretation, provide a clear indication of the need for cone biopsy.

CARCINOMA IN SITU The characteristic histological features of the lesion are complete loss of stratification and loss of cellular differentiation. The whole thickness of the epithelium is composed of closely packed, undifferentiated cells, but the basement membrane is intact and the epithelium is sharply delineated from the underlying connective tissue.

Rete pegs are rarely seen. There is loss of polarity, cells lying obliquely or at right angles to their usual axis, often producing a completely haphazard arrangement. There is poor cellular cohesion, so that the upper layers may appear frayed and incomplete. Occasionally there are a few flattened cells on the surface of the epithelium but, as already noted, this does not represent true stratification.

The cells are basophilic with an upset in nucleocytoplasmic ratio, so that the nucleus is relatively large and the cytoplasm inconspicuous. Generally the cells are pleomorphic, but on occasion they have a uniformity reminiscent of basal cell carcinoma. As a rule the nuclei are irregular in shape and hyperchromatic. Mitoses may be abundant or infrequent; when present a high proportion are bizarre.

The smear in carcinoma in situ usually contains a large number of abnormal cells. Often some of these are in ribbons or sheets, for the epithelium is fragile and easily removed with the spatula. The cells vary in shape and size. The most characteristic cell, however, is rounded, about the size of a normal basal cell, but has a much larger nucleus occupying more than half the cell. Apart from its greater size, the nucleus differs very much from that of a basal cell in that there is hyperchromasia with coarse, blotchy clumping of the chromatin and indentation and thickening of the nuclear membrane. Nuclei are often crenated and some are multilobed. The cytoplasm, unlike that of dyskaryotic cells, is not plentiful, but the cell outlines are usually distinct. Nevertheless it must be emphasized that carcinoma in situ and various degrees of dysplasia often coexist in one and the same cervix. Thus the smear in carcinoma in situ frequently contains an admixture of dyskaryotic cells.

ENDOCERVICAL GLAND INVOLVEMENT The mucous glands of the cervix are frequently involved in carcinoma in situ and in severe dysplasia, but only occasionally in mild dysplasia. Usually the abnormalities in the epithelium lining the glands correspond to those of the surface epithelium, but the changes in the glands may appear the more severe. Sometimes this may be due to tangential cutting, and further sections should be examined before the lesion is classified. This is particularly important in a cone biopsy when the fragile surface epithelium has been lost and only the glandular extensions remain for assessment. This may result from manipulation before or during operation or in the course of laboratory processing.

In our opinion the outcome is not affected by the presence or absence of mucous gland involvement. Such involvement can, however, be mistaken for invasive carcinoma. This error is especially possible when the plane of section shows no continuity between the involved gland and the surface epithelium and when the gland lumen appears completely filled by the abnormal epithelium. The smooth symmetrical outlines of the glands help to distinguish this change from true invasion, and the difficulty may be resolved if additional sections reveal remnants of a lumen or of its original columnar cell lining.

MICROCARCINOMA We regard microcarcinoma as minimal stromal invasion stemming from carcinoma in situ. The clumps and tongues of abnormal epithelial cells which infiltrate the cervical stroma in microcarcinoma have not the smooth rounded contours seen when carcinoma in situ merely involves gland crypts; in contrast, they have irregular, spiky outlines. Their cells fray out into the connective tissues, and often the surrounding collagen is condensed. A further diagnostic feature is that the invading cell masses often show at their centres a 
FIG. 22.

FIG. 23.

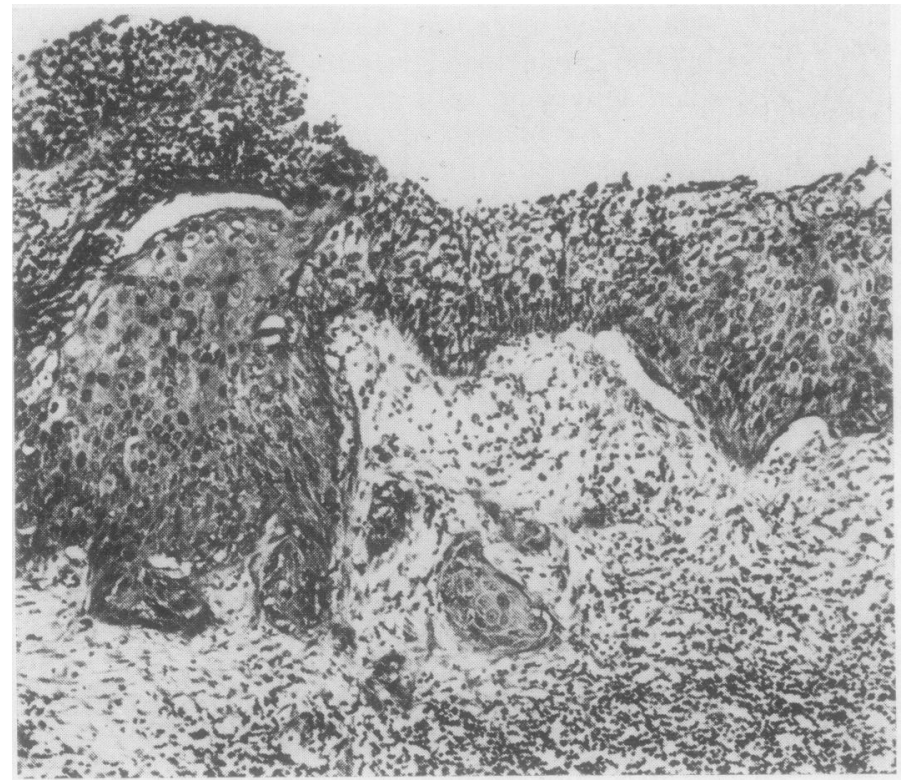

FIG. 22. Malign epithelium in glands: the epithelium in the involved glands appears to be more abnormal than that 윽 on the surface.

FIG. 23. Gland involvement: carcinoma in situ involves glands but their contourso are preserved.

FIG. 24. Microcarcinoma: beneath the carcinoma in situ there are buds of $O$ malignant epithelium invading the cervicat stroma. 

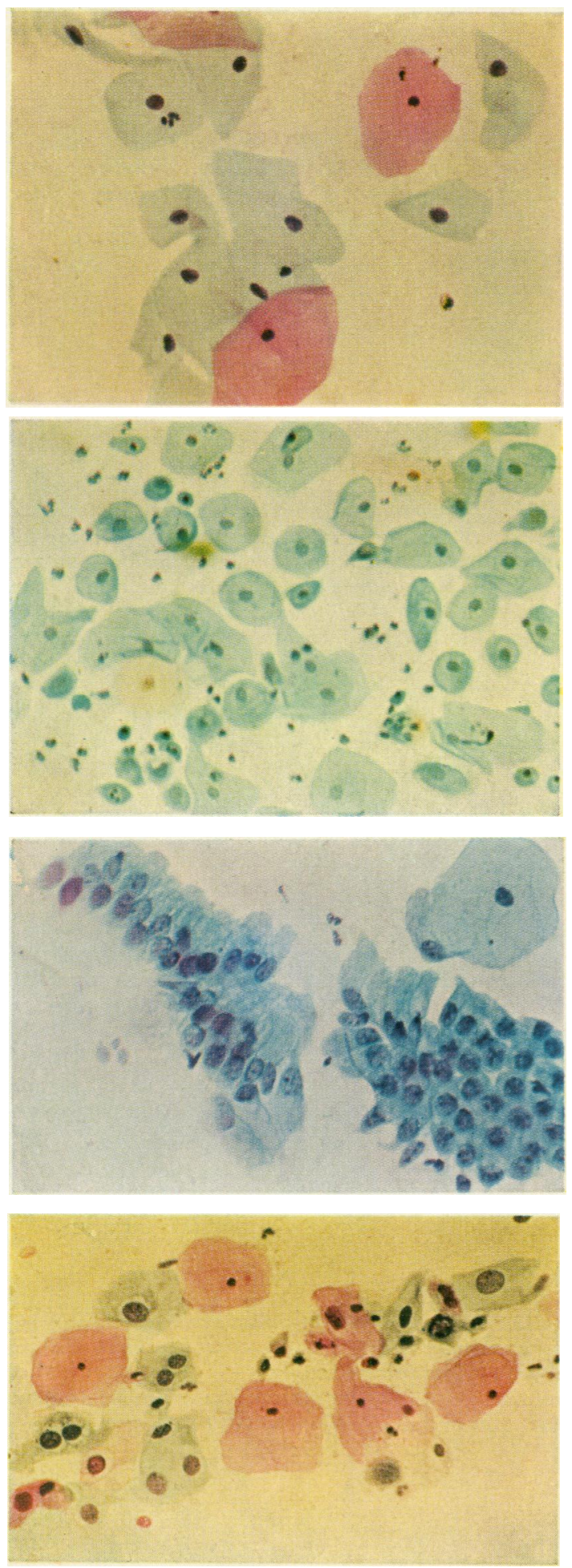

FIG. 25. Normal squames: a mixture of superficial (eosinophilic) squames with tiny pyknotic nuclei and intermediate (cyanophilic) squames with slightly larger vesicular nuclei.

FIG. 26. Normal basal cells: the cells have rounded borders, are cyanophilic, and have regular small vesicular nuclei.

FIG. 27. Normal endocervical cells: the cells cluster and may be seen cither as columnar cells with peg-like processes at the lower pole and with basal rounded vesicular nuclei, or as a sheet of closely packed cells with uniform nuclei and prominent nucleoli.

FIG. 28. Dyskaryotic cells: the cells have adequate cytoplasm and slightly enlarged nuclei, some with peri-nuclear haloes; most of the nuclei are smooth and rounded but some are irregular due to degeneration. The nuclear chromatin may be clumped or granular. A few typical squames with small pyknotic nuclei contrast with the dyskaryotic cells. The smear should be related to the histology seen in Fig. 14, illustrating 'mild dysplasia'. 

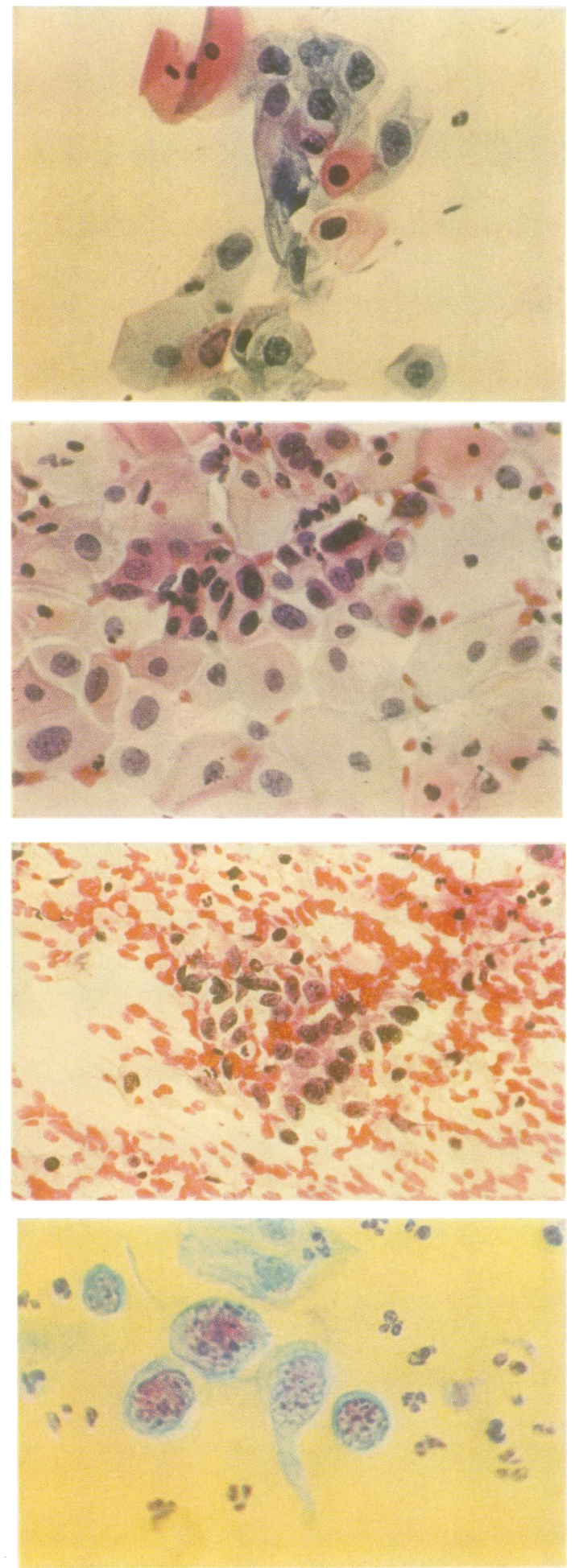

FIG. 29. Dyskaryotic cells: the cells have enlarged irregular nuclei with coarsely distributed chromatin; some of the nuclei are pyknotic. Compare with the normal squame present.

FIG. 30. Dyskaryotic cells: the picture contains a mixture of normal and dyskaryotic cells. At the centre the cells with hyperchromatic nuclei are very abnormal and illustrate the difficulty of distinguishing severe degrees of dysplasia from carcinoma in situ. The smear should be related to the histology seen in Fig. 17, illustrating 'severe dysplasia'.

FIG. 31. Malignant cells: a cluster of pleomorphic malignant cells with scanty cytoplasm and coarsely distri. buted chromatin in the nuclei. The cells are surrounded by red blood cells. The smear should be related to the histology seen in Fig. 19, illustrating 'carcinoma in situ'.

FIG. 32. Malignant cells: a higher power picture showing in more detail the bizarre shapes of the cells and the $\bar{\Phi}$ coarse irregular distribution of nuclear chromatin typical of $\stackrel{\oplus}{?}$ malignant cells. The smear should be related to the his- $\square$ tology seen in Fig. 20, illustrating 'carcinoma in situ'. 
degree of differentiation amounting to prickle cell formation.

Microcarcinoma is not distinguishable from carcinoma in situ in the cervical smear.

\section{DISCUSSION}

Bland and malign lesions are not infrequently both present in the same cervix, but there is no well established evidence that this is other than coincidental. As regards malign lesions, it has already been emphasized that the relationship of dysplasia and carcinoma in situ to invasive carcinoma requires much further study. There is equal uncertainty about the relation between dysplasia and carcinoma in situ. These lesions may coexist in a cervix, but the combination is by no means invariable, nor is it established that there is a progression from one to the other. Certainly, follow-up studies suggest that mild dysplasia quite often regresses, especially when it accompanies infection with trichomonas or occurs in pregnancy. Severe dysplasia is of much more serious import. Histologically it may be extremely difficult to distinguish from carcinoma in situ and there is no proof that it has any less potential for developing into invasive carcinoma.

The prime function of cervical cytology is in bringing to notice epithelial abnormalities which would otherwise escape detection because of their clinical silence. Cytology does not provide a definitive diagnosis, for this can only be achieved by biopsy, especially when more than one lesion is present. However, it does give sufficient information about the changes in the epithelium for a decision to be made on the need for biopsy. The area of maximum instability in the cervical epithelium is at the squamo-columnar junction and it is in this region that malign lesions usually first appear. Therefore, when cervical biopsy is required, either following an abnormal smear or for some clinical reason, a liberal cone which includes the squamocolumnar junction and adjacent tissues around the whole circumference of the external os, is the only adequate specimen. Ring biopsy often provides insufficient material. The whole cone must be examined by dividing it into multiple blocks and studying sections from each. When dysplasia or carcinoma in situ is found, it is of great importance to be sure that there is not coexistent invasive carcinoma. Any block from which the initial slide shows suspicious areas must be step-sectioned or cut serially. Cytology is of further value after cone biopsy. Provided that invasive carcinoma has been excluded and that the whole of the abnormal epithelium appears to have been removed, a patient may be followed up and smears can be used to ensure that any residual or recurrent lesion is detected promptly. Thus cytological examination and cone biopsy, used as complementary techniques, are not only the main source of material for elucidating the natural history and prognosis of dysplasia and carcinoma in situ of the cervix, they are also essential to the diagnosis, treatment, and management of these conditions.

Our thanks are due to the Editor of the Journal of Obstetrics and Gynaecology of the British Commonwealth for permission to reproduce Figures 3, 4, 6, 23, and 24 .

\section{REFERENCE}

Govan, A. D. T., Haines, R. M., Langley, F. A., Taylor, C. W., and Woodcock, A. S. (1966). J. Obstet. Gynaec. Brit. Cwlth, 73, 883 . 